\title{
Sudden infant death syndrome: does winter affect poor and rich babies equally?
}

\author{
Anne Buvé, Laura C Rodrigues
}

\begin{abstract}
Study objective-The aim was to investigate whether the winter increase in risk of sudden infant death was similar across social classes.
\end{abstract}

Design-This was an unmatched casecontrol study using routine data.

Setting-Cases and controls were selected from files holding routine birth and death certificate data for England and Wales for 1986.

Subjects-Cases were deaths in the first year of life occurring in the summer or the winter of 1986 with mention of sudden infant death or SIDS in the death certificate. Controls were a $1 \%$ random sample of all children born in the same year. Only children whose parents were married or living together at the time of birth registration were included.

Main results-Data on age and season of death for cases, and on date of birth, social class of father, and birth weight were abstracted from the file. Season of birth and birth weight were treated as confounding variables. The increase in risk of SIDS in winter was calculated for each age group and social class. The winter increase in SIDS was more marked among the higher social classes for all ages, but not to a statistically significant degree: the $p$ values for heterogeneity were 0.26 for age $0-3$ months, 0.42 for 4-7 months, and 0.41 for 8-12 months.

Conclusions-There is no direct association between seasonal variation in sudden infant death and social class.

f Epidemiol Community Health 1992; 46: 485-488

Seasonal variation in mortality has been described since Hippocrates. ${ }^{1}$ It is a subject that appears not only in the medical literature, but also attracts considerable media attention. ${ }^{2}$ In the United Kingdom politicians have been challenged about cold related deaths among the elderly.

Several studies have shown an association between excess mortality and cold. ${ }^{3-5}$ However there are large differences in seasonal mortality between different countries and these differences are not completely explained by climatic factors. ${ }^{6}$ In 1978 , winter related deaths made up $12 \%$ of the total number of deaths in England and Wales, as opposed to only $4 \%$ in Canada. It has been suggested that the percentage of cold related deaths is to some extent an index of poverty. ${ }^{7}$ The winter ratio among adults (ie, the ratio of the annual equivalent mortality rate for January to March to the yearly mortality rate) decreased in England and
Wales between the years 1959-1963 and 19701972 and is more marked in lower social classes. ${ }^{89}$

Excess mortality in winter is most marked among the elderly and infants. The sudden infant death syndrome (SIDS) is the most common certified cause of postneonatal mortality; in 1986 $45 \%$ of postneonatal deaths were attributed to SIDS. ${ }^{10}$ The risk of SIDS increases with decreasing social class and shows a strong seasonal variation, about twice as many babies dying in winter than in summer. ${ }^{31-16}$ It has been suggested that the factors responsible for the seasonal variation in SIDS interact with adverse social factors to increase the excess winter mortality from SIDS in high risk infants. ${ }^{17}$ We explored the hypothesis that the seasonal variation in sudden infant death syndrome is related to social class, by examining the interaction between season and social class as risk factors for SIDS.

\section{Methods}

Data on all infant deaths classified as SIDS, and a $1 \%$ sample of all births in England and Wales in 1986, were obtained from the Office of Population Censuses and Surveys (OPCS). For the purpose of this study we used the OPCS definition of "SIDS mention" which classifies a death as SIDS if "sudden infant death" or "cot death" or a similar phrase is mentioned anywhere on the death certificate. Information on the following variables was obtained from the OPCS birth and death certificates: date of birth, social class of the father as defined by the Registrar General, and birth weight. In addition the following information was obtained for the deaths: date of death, ICD code of the underlying cause of death, and mention of SIDS.

The main exposures under study were social class of the father and season of death. Only babies whose parents were married or were living together though unmarried, were included in the analysis. Winter was defined as the period from 1 December till 31 March, summer as the period from 1 June till 30 September. Only deaths occurring during those two periods were included in the analysis.

Deaths were classified according to the date of death into three age groups and two seasons of death. For each combination of age at death and season, a control group was identified including all children from the $1 \%$ sample of births who were born in the same time period as the SIDS cases. The datasets were analysed as a series of case-control studies with SIDS as the outcome. The analyses were carried out separately for each age group. This was necessary to prevent a control 


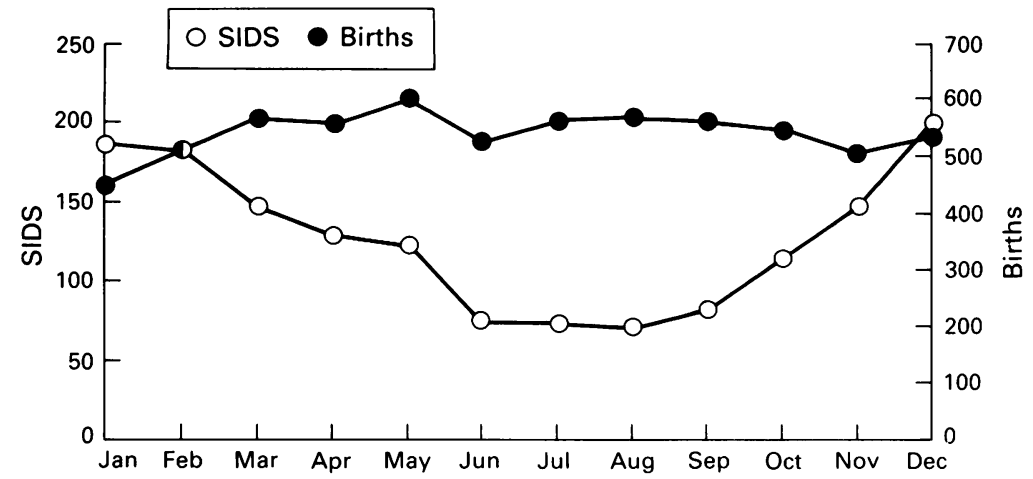

SIDS by month of death and births by month of birth.

Table I Relative risks of SIDS in winter compared to summer stratified by age

\begin{tabular}{llccc}
\hline Age & & Winter & Summer & $R R$ \\
\hline 0-3 months & Cases & 433 & 193 & \\
& Controls & 4309 & 4439 & $2 \cdot 3$ \\
4-7 months & Cases & 206 & 89 & \\
& Controls & 4414 & 4334 & $2 \cdot 3$ \\
8-11 months & Cases & 47 & 14 & \\
& Contols & 4367 & 4317 & $3 \cdot 3$ \\
\hline
\end{tabular}

$\mathrm{RR}=$ relative risk
Test of heterogeneity for the odds ratios: $\chi^{2}=0.26$ on $2 \mathrm{df}$, $\mathrm{p}>0.5$

Mantel-Haenszel summary $R R=2 \cdot 4$

from being counted twice in the same contingency table. Had we not stratified, a birth occurring in October 1986, for instance, would have been counted as control for a 2 month old baby dying in December 1986 and a 7 month old baby dying in April 1986.

To explore the interaction between social class and season of death, each dataset was analysed twice. Firstly, the relative risk of SIDS in children in each social class, using the highest social class as the baseline, was estimated separately for each age group and season. Secondly, the relative risk of SIDS in winter, as opposed to summer, was estimated separately for each combination of social class and age group. To assess whether there is interaction between social class and season we tested for homogeneity separately for each age group, as the data were too sparse to test for interaction in the logistic regression model, taking age into account.

Month of birth and birth weight were treated as potential confounding variables. Allowance was made for the social class specific seasonal varation in births by carrying out the analysis stratified by age. The confounding effect of birth weight was assessed using logistic regression. A logistic regression model was fitted to the data using death from SIDS as the outcome and social class and month of birth as the explanatory variables. A test was then performed to see whether adding birth weight as an explanatory variable changed the relative risks for social class and for month of birth, and thus to see whether birth weight needed to be included in further analysis. The software package used to perform the test for homogeneity was Statxact and the logistic regression was Egret.

\section{Results}

In 19861500 infant deaths were attributed to "sudden infant death syndrome". The number of live births in that year was 661018 . Thus in 1986 the risk of SIDS was 2.3 per 1000 births.
The figure shows the distribution of births by month of birth and of SIDS by month of death. Though there was only a small seasonal variation in the number of births (slightly more babies being born in spring and in summer than in autumn and in winter) the ratio of the number of SIDS cases occurring in winter to the number of cases occurring in summer was $2 \cdot 3$. In table I we present the increase in risk of SIDS in winter separately for each age group irrespective of social class of father. This is the same for children aged 0 to 3 months and 4 to 7 months. It is larger but not to a statistically significant degree $(p>0.5)$, among children aged 8 to 11 months. As the test of heterogeneity between the relative risks was not significant, a Mantel-Haenszel weighted average of the relative risks was calculated. The relative risk was $2 \cdot 4$, hardly different from the ratio of the number of SIDS in winter to the number of SIDS in summer.

Table II shows the relative risks of SIDS by social class of the father, using social class I as the baseline, independent of season of death. The risk of SIDS was higher among the lower social classes. The overall test of heterogeneity was highly significant. However, the relative risk for social classes I to IIIM were not statistically significantly different from each other $\left(\chi^{2}=3.46\right.$ on $3 \mathrm{df}$ ). Likewise the relative risks for the social

Table II Social class as risk factor for SIDS

\begin{tabular}{lcccccccc}
\hline & \multicolumn{3}{c}{ Social class } & & & & & \\
\cline { 2 - 8 } \cline { 5 - 8 } & $I$ & $I I$ & $I I I N$ & $I I I M$ & $I V$ & $V$ & $O$ \\
\hline SIDS & 65 & 199 & 84 & 360 & 206 & 92 & 94 \\
Births & 442 & 1272 & 603 & 2095 & 834 & 367 & 256 \\
OR $^{\mathrm{a}}$ & 1.00 & 1.06 & 0.95 & 1.17 & 1.68 & 1.70 & 2.50 \\
RR $^{\mathrm{b}}$ & 1.00 & 1.03 & 1.07 & 1.19 & 1.48 & 1.65 & 2.07
\end{tabular}

aOdds ratio for SIDS.

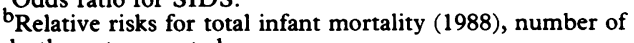
deaths not presented.

Test for trend: $\chi^{2}=50.14$ on $1 \mathrm{df}, \mathrm{p}<0.001$

classes IV and $\mathrm{V}$ were not significantly different $\left(\chi^{2}=0.01\right.$ on $\left.1 \mathrm{df}\right)$. Because of this social classes were regrouped into categories: professional and skilled workers, semiskilled and unskilled workers, and others. Table III shows the relative risk for the regrouped social classes. The test for trend is highly significant.

The mean birth weight for the $1 \%$ sample of births was 3.300(SD 565) g; for the SIDS it was $3.069(682) \mathrm{g}$. The difference between these mean birth weights is statistically significant $(t=13.7$ on $8037 \mathrm{df}, \mathrm{p} \ll 0.001)$, indicating that there is an association between birth weight and SIDS. For babies with a birth weight between 2000 and $2500 \mathrm{~g}$ the risk of SIDS was 1.8 times greater than the risk for babies with a birth weight equal to or greater than $2500 \mathrm{~g}$; for babies with a birth weight under $2000 \mathrm{~g}$ the risk was 4.6 times greater. However adding birth weight to the logistic model with month of birth and social class of father as explanatory variables hardly changed the relative risks for either month of birth or social class. In the model the odds ratio for the class "semiskilled or unskilled" changed from 1.72 to 1.65 after adding birth weight, for the class "other" it changed from 2.93 to $2 \cdot 72$. The risk of being born in September-October compared to being born in March-April changed from 2.32 to $2 \cdot 28$. This led to the conclusion that birth weight was not 
Table III Social class as risk factor for SIDS (regrouped social classes)

\begin{tabular}{lccc} 
& "Professional & "Semiskilled or & "Other" \\
& or skilled" & unskilled" & (others) \\
& $(I, I I, I I I)$ & $(I V, V)$ & 94 \\
SIDS & 708 & 298 & 256 \\
$1 \%$ Sample of births & 4412 & 1201 & $2 \cdot 3$ \\
Relative risk & 1.0 & $1 \cdot 6$ & \\
\hline
\end{tabular}

Test for trend: $\chi^{2}=349.28$ on $1 \mathrm{df}, \mathrm{p}<0.001$

modifying the association between SIDS on the one hand and season and social class on the other. Because of this the analysis was now based on the two latter risk factors and single cross tabulations were used.

Table IV gives the numbers of cases and controls stratified by age, season (of death), and social class. The tables V, VI, and VII are derived from this table. Table $\mathrm{V}$ gives the relative risks of SIDS associated with social class, stratified by age and by season. In each age stratum the social class gradient was steeper in summer than in winter. Within each age group and each social class the relative risks for summer and for winter are not significantly different, but the same pattern of steeper social class gradient in summer than in winter was found in each age group.

Table IV Cases and controls by age, season of death and social class

\begin{tabular}{|c|c|c|c|c|c|}
\hline \multirow[b]{2}{*}{$\begin{array}{l}\text { Age } \\
\text { (months) }\end{array}$} & \multirow[b]{2}{*}{ Season } & & \multicolumn{3}{|l|}{ Social class } \\
\hline & & & $\begin{array}{l}\text { Professional } \\
\text { or skilled }\end{array}$ & $\begin{array}{l}\text { Semiskilled or } \\
\text { unskilled }\end{array}$ & Other \\
\hline$\overline{0-3}$ & $\begin{array}{l}\text { Summer } \\
\text { Winter }\end{array}$ & $\begin{array}{l}\text { Cases } \\
\text { Controls } \\
\text { Cases } \\
\text { Controls }\end{array}$ & $\begin{array}{r}94 \\
3012 \\
201 \\
2873\end{array}$ & $\begin{array}{r}39 \\
794 \\
84 \\
788\end{array}$ & $\begin{array}{r}19 \\
182 \\
23 \\
174\end{array}$ \\
\hline $4-7$ & $\begin{array}{l}\text { Summer } \\
\text { Winter }\end{array}$ & $\begin{array}{l}\text { Cases } \\
\text { Controls } \\
\text { Cases } \\
\text { Controls }\end{array}$ & $\begin{array}{r}34 \\
2909 \\
90 \\
3000\end{array}$ & $\begin{array}{r}21 \\
816 \\
39 \\
794\end{array}$ & $\begin{array}{r}7 \\
156 \\
11 \\
176\end{array}$ \\
\hline $8-11$ & $\begin{array}{l}\text { Summer } \\
\text { Winter }\end{array}$ & $\begin{array}{l}\text { Cases } \\
\text { Controls } \\
\text { Cases } \\
\text { Controls }\end{array}$ & $\begin{array}{r}6 \\
2903 \\
24 \\
2951\end{array}$ & $\begin{array}{r}4^{a} \\
966 \\
7 \\
982\end{array}$ & \\
\hline
\end{tabular}

aSocial classes "semiskilled or unskilled" and "other" were combined in age group 8-11 because of small numbers.

Table VI presents the ratio of the risk of dying from SIDS in winter to dying from SIDS in summer for each social class and age group. The smallest ratio $(1 \cdot 3)$ was found among children up to 4 months and with fathers in the "others" social class. The largest ratio (3.9) was found among children 8-11 months old, whose fathers were professionals or skilled workers. Although the tests of heterogeneity in each age group do not show a statistically significant difference, the trend of decreasing relative risks with decreasing social class was present in all age groups.

Table VII presents the attributable risk of SIDS in winter compared to summer, for each

Table $V$ Relative risks of SIDS by social class in summer and in winter

\begin{tabular}{|c|c|c|c|c|}
\hline \multirow[b]{2}{*}{$\begin{array}{l}\text { Age } \\
\text { (months) }\end{array}$} & \multirow[b]{2}{*}{ Season } & \multicolumn{3}{|l|}{ Social class } \\
\hline & & $\begin{array}{l}\text { Professional } \\
\text { or skilled }\end{array}$ & $\begin{array}{l}\text { Semiskilled or } \\
\text { unskilled }\end{array}$ & Other \\
\hline \multirow[t]{2}{*}{$0-3$} & Summer & $1 \cdot 0$ & \multirow{2}{*}{$\begin{array}{l}1 \cdot 6 \\
(1 \cdot 1-2 \cdot 3)^{a} \\
1 \cdot 5 \\
(1 \cdot 2-2 \cdot 0)\end{array}$} & \multirow{2}{*}{$\begin{array}{l}3 \cdot 3 \\
(2 \cdot 0-5 \cdot 5) \\
1 \cdot 9 \\
(1 \cdot 2-3 \cdot 0)\end{array}$} \\
\hline & Winter & $1 \cdot 0$ & & \\
\hline \multirow[t]{2}{*}{ 4-7 } & Summer & 1.0 & \multirow{2}{*}{$\begin{array}{l}2 \cdot 0 \\
(1 \cdot 3-3 \cdot 8) \\
1 \cdot 6 \\
(1 \cdot 1-2 \cdot 4)\end{array}$} & \multirow{4}{*}{$\begin{array}{l}3 \cdot 8 \\
(1 \cdot 7-8 \cdot 8) \\
2 \cdot 1 \\
(1 \cdot 1-4 \cdot 0)\end{array}$} \\
\hline & Winter & 1.0 & & \\
\hline \multirow[t]{2}{*}{$8-11$} & Summer & 1.0 & \multirow{2}{*}{$\begin{array}{c}2 \cdot 0^{\mathrm{b}} \\
(0 \cdot 6-7 \cdot 1) \\
0 \cdot 9 \\
(0 \cdot 4-2 \cdot 0)\end{array}$} & \\
\hline & Winter & 1.0 & & \\
\hline
\end{tabular}

a In brackets: $95 \%$ confidence interval of the relative risks. "Social classes "semiskilled or unskilled" and "other" were combined in age group 8-11 because of small numbers. social class and age group. There is no evidence of an increase in the attributable risk with decreasing social class.

In summary, there was no evidence in these data of a greater winter increase in SIDS among the lower social classes.

\section{Discussion}

This analysis was restricted to one year, 1986. This raises the possibility that the pattern identified was peculiar to this year, and is not a general feature of SIDS. In fact, the winter of 1985-1986 was exceptionally cold. There was a higher than expected number of SIDS in this year, which was attributed to the low temperature. ${ }^{5}$

Watson ${ }^{18}$ found that at least $20 \%$ of the infant deaths certified as SIDS do not fall within the definition of SIDS. If the percentage of false positives was different in the different social classes or in the different seasons, our results would have been biased. Bartholomew et al $^{19}$ found no differential misclassification in the diagnosis of SIDS according to social class. We looked at the underlying cause of death in SIDS mentions as a measure misclassification. Eight percent of SIDS mentions in winter, but only $2 \%$ in summer, had an infection as the underlying cause of death. This suggests the likelihood of a small seasonal variation in misclassification of SIDS. However, differential misclassification on the lines identified in the exercise above would only increase the social class gradient in excess mortality and therefore could not explain our findings.

Table VI Relative risks of SIDS in winter compared to summer, by age and social class

\begin{tabular}{|c|c|c|c|}
\hline \multirow[b]{2}{*}{ Age } & \multicolumn{3}{|l|}{ Social class } \\
\hline & $\begin{array}{l}\text { Professional } \\
\text { or skilled }\end{array}$ & $\begin{array}{l}\text { Semiskilled } \\
\text { unskilled }\end{array}$ & Other \\
\hline \multicolumn{4}{|c|}{$\begin{array}{c}(1 \cdot 7-2 \cdot 9)^{\mathrm{a}} \\
\text { Test of heterogeneity: } \chi^{(2 \cdot 5-3 \cdot 2)}=2 \cdot 7 \text { on } 2 \mathrm{df}, \mathrm{p}=0.10\end{array}$} \\
\hline \multicolumn{4}{|c|}{$\begin{array}{c}(1 \cdot 7-3 \cdot 8) \\
\text { Test of heterogeneity: } \chi^{2}=1 \cdot 71 \text { on } 2 \mathrm{df}, \mathrm{p}=0.43\end{array}$} \\
\hline $\begin{array}{r}\text { 8-11 month } \\
\text { Test }\end{array}$ & $\begin{array}{l}3 \cdot 9 \\
(1 \cdot 6-9 \cdot 6) \\
f \text { heterogen }\end{array}$ & 1.71 on & $\begin{array}{l}\text { 9) } \\
=0.28\end{array}$ \\
\hline
\end{tabular}

${ }^{2}$ In brackets; $95 \%$ confidence interval of the relative risks. bsocial classes "semiskilled of unskilled" and "other" were combined in age group 8-11 because of small numbers.

We only controlled for two potential confounding variables, month of birth and birth weight. We did not find evidence in published reports of seasonality in other risk factors for SIDS that are associated with social class. Maternal age has been shown not to be seasonal. ${ }^{16}$ Thus it is unlikely that out findings were the results of confounding.

Our results are in contrast to $\mathrm{McDowall}^{\mathrm{s}} \mathrm{s}^{8}$ and Curwen's, ${ }^{9}$ who found a greater excess of winter deaths in adults in the lower social classes. However, they analysed overall adult mortality.

Table VII Attributable risks (per 100000 ) of SIDS in winter compared to summer, by age and social class

\begin{tabular}{|c|c|c|c|}
\hline \multirow[b]{2}{*}{$\begin{array}{l}\text { Age } \\
\text { (months) }\end{array}$} & \multicolumn{3}{|l|}{ Social class } \\
\hline & $\begin{array}{l}\text { Professional } \\
\text { or skilled }\end{array}$ & $\begin{array}{l}\text { Semiskilled or } \\
\text { unskilled }\end{array}$ & Other \\
\hline $\begin{array}{l}0-3 \\
4-7 \\
8-11\end{array}$ & $\begin{array}{r}38 \\
18 \\
6\end{array}$ & $\begin{array}{l}57 \\
23\end{array}$ & $\begin{array}{l}28 \\
18\end{array}$ \\
\hline
\end{tabular}
combined in age group 8-11 because of small numbers. 
We did not find an increase in excess winter deaths from SIDS with decreasing social class. A possible explanation for this could be that one or more of the risk factors for SIDS which are behind the social class gradient have a stronger effect, or are more prevalent, in summer than in winter. An example of such a mechanism is described below. Overheating due to excessive bedding has been suggested as an aetiological factor for SIDS. The average thermal resistance of bedding and clothing of infants has been shown to increase with decreasing social class. ${ }^{20}$ This effect could be offset by colder temperatures in winter inside poor homes, and result in a less marked social class gradient in winter. Alternatively it has been suggested that what is now diagnosed as SIDS is a mixture of different disease entities. ${ }^{21}$ Our findings are consistent with this if there is a higher proportion of seasonal "causes" of SIDS among children born to fathers of higher social class.

More studies from different years and different geographical areas are necessary to confirm our findings; we are at the moment looking at the interaction between seasonality of SIDS and social class of mother among children of single parent households. Our results reject, for SIDS, the suggestion of a direct association between seasonal variation and standard of living. ${ }^{1722}$ Further research is needed to clarify which factors associated with social class and with cold play an aetiological role in SIDS. Meanwhile our results add to the criteria against which new hypotheses regarding the aetiology of SIDS should be tested.

These findings offer an explanation for the fact that the social class gradient in risk of SIDS in 1978 was steeper than in $1986 .{ }^{10}$ The winter months of 1986 were exceptionally cold and during the month of February more SIDS occurred than would have been expected from the data collected from 1979 to $1985 .^{5}$ The findings of the study suggest that relatively fewer babies of lower social class died in the cold winter months of 1986, resulting in a less steep social class gradient in risk of SIDS for the year 1986 .

When assessing the interaction between season and social class, two risk factors that represent a cluster of risk factors, the aim cannot be to unravel the aetiological mechanism(s) of SIDS. The relevance of the findings of the study lies in the fact that they complete the description of social class and season as risk factors for SIDS. Any hypothesis regarding the aetiology of SIDS has to be compatible with this description. The findings of the study, for instance, suggest that the relation between social class and SIDS on the one hand and cold and SIDS on the other is more complicated than the hypothesised chain of events, with low social class leading to poor housing, exposure to cold, and SIDS. Improvement in housing and heating facilities might not have an impact on the seasonal variation in the incidence of SIDS. The attributable risk of SIDS in winter compared to summer was about the same for the lower social classes as for the higher social classes. However, this should not detract from the fact that social class remains a very important risk factor for SIDS and unfortunately there is no indication that poverty and its effects on health are decreasing.

This study illustrates that social class as a risk factor for certain disorders cannot be explained by simple aetiological mechanisms. Social class stands for a group of characteristics ranging from material environment to behaviour patterns. The contribution of each individual risk factor to disease causation should be assessed by way of multiple regression analyses. There is still a need for more such analyses in the search for the aetiology of SIDS and the identification of targeted preventive measures.

Lastly the relation between illegitimacy and risk of SIDS is interesting. Further exploration of this relation could lead to an assessment of the relative importance of the material environment and behaviour patterns in the causation of SIDS.

We are grateful to Professor J Fox for granting access to OPCS routine data, and Alice Dickens for typing this manuscript. We would like to thank J Fox, A McFarlane, B Botting, P Fine, A Hall, and D Leon for helpful comments on an earlier draft.

1 Lloyd GER, ed. Hippocratic writings. London: Penguin 1978.

2 Anonymous. Cold deaths to top 60,000 a year. The Times, 16 May 1969: 2 .

3 Bonser RSA, Knight BH, West RR. Sudden infant death syndrome in Cardiff, association with epidemic influenza and with temperature-1955-1974. Int $\mathcal{F}$ Epidemiol 1978; 7 : $335-40$.

4 Murphy MFG, Campbell MJ. Sudden infant death syndrome and environmental temperature: an analysis using vital statistics. I Epidemiol Community Health 1987; 41: 63-71.

5 Campbell MJ, Rodrigues LC, Macfarlane A, Murphy M. Sudden infant deaths and cold weather: was the rise in infant mortality in 1986 in England and Wales due to the infant mortality in 1986 in England and weather? Paediatr Perinat Epidemiol 1992; 5: 93-100.

6 McFarlane A. Seasonal variation in postneonatal mortality. Studies on medical and population subjects No 45 London: HMSO, 1982.

7 Grut $M$. Cold-related deaths in some developed countries. Lancet 1987; i: 212.

$8 \mathrm{McD}$ owall M. Long term trends in seasonal mortality. Popul Trends 1981; 26: 16-9.

9 Office of Population Censuses and Surveys. Trends in respiratory mortality 1951-75. (Series DH1 No 7). London: OPCS, 1981.

10 Registrar General. Mortality statistics. Perinatal and infant: social and biological factors. Review of the Registrar General of England and Wales, 1986. Series DH3 No 20. London: HMSO, 1988 .

11 Fedrick J. Sudden unexpected death in infants in the Oxford Record Linkage Area: the mother. Br f Prev Soc Med 1974; 28: 93-7.

12 Adelstein AM, MacDonald Davies IM, Weatherall JAC White GC. Sudden infant death: social, biological and regional factors. Studies on medical population subjects $\mathrm{No}$ 45. London: HMSO, 1982

13 Mason JK, Park RJ, Boyd GS. Cot deaths in Edinburgh infant feeding and socioeconomic factors. I Epidemio Community Health 1980; 34:35-41.

14 Fedrick J. Sudden unexpected death in infants in the Oxford Record Linkage Area. An analysis with respect to time an place. Br F Prev Soc Med 1973; 27: 217-24.

15 Carpenter R, Gardner A. Variations in unexpected infant death rates relating to age, sex and season. Studies on medical and population subjects No 45. London HMSO, 1982.

16 Osmond C, Murphy M. Seasonality in the sudden infant Osmond C, Murphy M. Seasonality in the sudden infant death sy.

17 Carpenter RG, Gardner A. Environmental findings and Sudden Infant Death Syndrome. Lung 1990; suppl: $358-67$.

18 Watson $\mathrm{E}$. Changes in verdict of sudden infant death. Lancet 1985; i: 631 .

19 Bartholomew SEM, MacArthur BA, Bain AD. Sudden infant death syndrome in south east Scotland. Arch Dis Child 1987; 62: 951-6.

20 Fleming PJ, Gilbert R, Azaz Y, et al. Interaction between bedding and sleeping position in the suddent infant death syndrome: a population based case-control study. $B M \mathcal{J}$ 1990; 301: 85-9.

21 Nicholl JP, O'Cathain A. Epidemiology of babies dying at different ages from the sudden infant death syndrome. $f$ Epidemiol Community Health 1989; 43: 133-9.

22 McKee CM. Deaths in winter: Can Britain learn from Europe? Eur $\mathcal{F}$ Epidemiol 1989; 5: 178-82. 